Dossiê - Para além do “ativismo judicial" e da “judicialização da política" DOI: $10.5433 / 2176-6665.2016 \mathrm{v} 21 \mathrm{~N} 1 \mathrm{P} 167$

\title{
Ministério Público do Trabalho: construção INSTITUCIONAL E FORMAÇÃO DA AGENDA
}

\author{
KAREN ARTUR $^{1}$
}

\begin{abstract}
Resumo
Este artigo trata das mudanças organizacionais do Ministério Público do Trabalho (MPT) relacionadas à concretização do papel de agente atribuído pela Constituição Federal de 1988. O trabalho propõe que o encurtamento da distância entre a sociedade e o MPT tem envolvido a construção da legitimidade dos procedimentos e formas de atuação dos procuradores do trabalho coletivamente informadas. Apesar de conviver com um ambiente organizacional não propício às ações estratégicas, a atuação de um grupo dentro do MPT e a mobilização do direito por setores da sociedade civil têm permitido ações coordenadas, inclusive em outras arenas.
\end{abstract}

Palavras-chave: Ministério Público do Trabalho. Mudança institucional. Papel de agente. Agenda setting.

\section{Labor Prosecution Office: institutional making and agenda}

\section{SETTING}

\begin{abstract}
This article approaches the organizational changes of the Labor Prosecution Office (MPT) related to the achievement of the role of agent, which was assigned to it by the 1988 Federal Constitution. It proposes that the shortening of the distance between the society and the MPT involves the development of the legitimacy of its proceedings and the collective guided way the labor prosecutors operate. Although it coexists with an organizational environment which is not favorable to strategic actions, the activity of a group in the MPT and the mobilization of the civil society sectors have allowed coordinated action, even in other arenas.
\end{abstract}

1 Bolsista (PNPD/CAPES) do Programa de Pós-Graduação em Ciência Política da Universidade Federal de São Carlos (UFSCar), Brasil. karenartur2014@gmail.com 
Keywords: Labor prosecution office. Institutional change. Role of agent. Agendasetting.

\section{INTRODUÇÃo}

Com o advento da Constituição de 1988, o Ministério Público deixou de integrar os Poderes, passando a ser considerado como "essencial à função jurisdicional do Estado, incumbindo-lhe a defesa da ordem jurídica, do regime democrático e dos interesses sociais e individuais indisponíveis." (BRASIL, 1988, art. 127). Dentro dessas condições históricas e institucionais, a busca pela concretização de seu novo papel e a mobilização do direito têm estimulado mudanças organizacionais no Ministério Público do Trabalho (MPT), tornando-o mais um agente de políticas públicas. Este estudo trata da agenda da instituição, a qual se dá a partir de demandas sociais, de ações de membros do MPT e de suas coordenadorias. Tais coordenadorias promovem discussões sobre suas respectivas áreas, definem estratégias e articulam planos nacionais de ações.

Sem deixar de mencionar os estudos realizados por membros da instituição (CARELLI; CASAGRANDE; PÉRISSÉ, 2007), notam-se poucos estudos sobre o MPT. Diante da importância que a instituição tem no processo de introdução de argumentos de justiça social no direito (VIANNA et al., 1999), apresentamos esta pesquisa, a qual trata da atuação do MPT no pós-1988. Nela, buscamos considerar as relações entre interesses e ideias da instituição na promoção de direitos do trabalho, assim como as suas relações com outras instituições e atores coletivos na formação de sua agenda e estratégias de ação. Especificamente, investigamos suas mudanças organizacionais destinadas a promover ações estratégicas em função de políticas institucionais consideradas prioritárias. 
O material empírico constitui-se de entrevistas com procuradores do MPT que ocuparam posições em coordenadorias temáticas e na Procuradoria Geral do Trabalho², além de material editado pela instituiçãoe dados de sua atuação por ela disponibilizados. Foram observadas as interpretações dos agentes sobre a permeabilidade ao ambiente institucional e os dilemas organizacionais envolvidos (SCOTT, 2014).

Além dessa introdução, este artigo possui mais quatro partes e uma consideração final. Primeiramente, apresentamos as principais visões da literatura sobre a legitimidade do Ministério Público e como nossa pesquisa se vincula a uma delas. Em segundo lugar, tratamos da construção de ações estratégicas que visaram constituir o novo papel institucional do MPT. Em seguida, analisamos a opção institucional pelo uso de soluções extrajudiciais dentro de determinados modelos de atuação. Enfim, relacionamos a agenda da instituição nas coordenadorias temáticas à mobilização de setores da sociedade civil.

\section{A Legitimidade da Atuação do Ministério Público em Discussão}

Existem diferentes perspectivas sobre o fundamento da legitimidade institucional do Ministério Público, conforme analisa Maciel (2002). Na primeira perspectiva, tal fundamento encontra-se

2 Entre julho e dezembro de 2015, foram entrevistados: Sandra Lia Simón - ProcuradoraGeral do Trabalho (2003-2007); Luís Antonio Camargo de Melo - Procurador-Geral do Trabalho (2011-2015); Maurício Correia de Mello- atual Subprocurador-Geral do Trabalho/ Corregedor Geral do Trabalho, vice-coordenador da Coordinfância; Sebastião Vieira Caixetapresidente da ANPT por três mandatos; atual chefe de gabinete do Procurador-Geral do Trabalho e secretário de relações institucionais, ex-coordenador da Conaete; Christiane Vieira Nogueira: atual vice-coordenadora nacional da Conaete/ MPT-SP; Rafael de Araújo Gomes - Procuradoria Municipal de Araraquara/MPT Campinas, ex-membro da Conaete; Lisyane Chaves Motta-ex-coordenadora nacional da Coordigualdade; Rodrigo de Lacerda Carelli- excoordenador da Conafret/MPT-RJ; Alessandro Santos de Miranda- ex-coordenador nacional da Codemat, Janine Milbratz Fiorot- representante regional da Codemat/MPT-RJ. Também entrevistamos Xavier Plassat, da Comissão Pastoral da Terra, uma liderança no combate ao trabalho escravo. 
no ativismo voluntarista dos seus membros, o qual é pautado mais fortemente na visão da sociedade como hipossuficiente (ARANTES, 2002). Em uma segunda perspectiva, a legitimidade institucional do Ministério Público tem sua base nos valores e interesses no processo democratização e de abertura do processo político à sociedade civil, sendo mais um lócus de expressão de valores da cidadania (VIANNA et al., 1999). Para Maciel, contudo, essas perspectivas não problematizam a legitimação da atuação do Ministério Público frente aos: “[...] dilemas organizacionais surgidos da expansão e racionalização de novos direitos e identidades coletivas, seja em virtude da dinâmica de permeabilidade e impermeabilidade, e de cooperação e de conflito estabelecidas com o ambiente externo." (MACIEL, 2002, p. 10).

É dentro dessa última visão que procedemos à apresentação e à análise dos argumentos dos procuradores do trabalho entrevistados a respeito da legitimidade das mudanças organizacionais voltadas para a constituição do papel de agente do MPT e das opções procedimentais adotadas. Seguimos a sugestão de Maciel e Koerner (2002, p. 121) no sentido de que as afirmações dos membros do MP interpretadas na pesquisa de Arantes como reveladoras de um voluntarismo político podem remeter-se ao próprio desenho institucional do MP na Constituição de 1988. Nas entrevistas realizadas, ser agente não implica em ser substituto de uma sociedade hipossuficiente, mas sim ser responsável pelo desenvolvimento de ações estratégicas para que as novas atribuições constitucionais do MP se efetivem.

Com respeito à legitimidade das opções procedimentais, Maciel e Koerner (2002, p. 128) questionam se a procedimentalização dos direitos metaindividuais estaria sendo interpretada pelos profissionais das instituições judiciais segundo as práticas do positivismo privatista e dos seus interesses particulares. Por sua vez, Vianna e Burgos (2005, p. 785), analisando casos de ações civis públicas, destacam que as regras jurídicas estão tendo uma “interpretação à luz de princípios 
e valores constitucionais, ampliando o sistema de cidadania." Já a preponderância do uso de métodos extrajudiciais pelo MP levou Maciel a questionar a aplicação do conceito de judicialização como deslocamento de conflitos da esfera política para os tribunais. A autora apresenta uma "face desjudicializadora do MP", que é "marcada pela negociação e barganha, típica da esfera política, presente nas relações de cooperação estabelecidas com as arenas em arenas ambientais." (MACIEL, 2002, p. 104-105). Entendemos, assim, que as pesquisas empíricas devem tratar dos projetos institucionais em disputa no MP e abordar se os procedimentos extrajudiciais estão conseguindo promover cooperação e ampliar o sistema da cidadania.

Em análise sobre a atuação do Ministério Público na Constituinte, Maciel e Koerner (2014) defendem que, para além da atuação como lobby, o Ministério Público mostrou-se como uma alternativa institucional viável diante da construção doutrinária de interesse público e da sua interação com redes pró-democracia. Nesse sentido, a presente pesquisa também trabalha com a importância dos fatores exógenos que contribuíram para essa mudança organizacional, referentes aos atores e processos presentes no ambiente social mais amplo. Observamos, assim que a criação de coordenadorias e o desenvolvimento de seus projetos não são apenas frutos de um projeto institucional, mas também da mobilização do direito por movimentos sociais e entidades sindicais, entendida aqui como um tipo de ação pela qual os interesses, valores e demandas dos atores sociais e organizações foram traduzidos como uma questão de direitos constitutiva de seus discursos e estrategicamente direcionada (McCANN,1994) para também compor uma atuação coletiva do MPT.

Desse modo, entendemos que a construção institucional do MPT envolveu não apenas o uso de procedimentos judiciais e extrajudiciais, mas a definição de normas com os objetivos e os modos apropriados de segui-los (SCOTT, 2014). Com isso, buscou-se infundir 
valores unificadores entre os procuradores do trabalho, intensificar os propósitos coletivos e inserir a organização no ambiente social. Ao buscar superar os mecanismos individualizadores da ação, a agenda da instituição passou a ser composta de temas reconhecidos pelos pares e legitimados socialmente.

\section{Condições Institucionais para Atuação do MPT}

Arantes (2002) analisa o processo de reconstrução do papel do Ministério Público brasileiro desde os anos 70 a partir do tripé institucional expresso na legalização de direitos difusos e coletivos, na ação civil pública e na independência institucional, além de um componente ideológico. Seu trabalho constituiu-se na primeira corrente interpretativa da atuação do MP, a qual o apresenta como uma instituição dotada de uma missão tutelar da sociedade, analisada por meio do conceito de "voluntarismo político".

Tal conceito se refere às concepções ideológicas dos seus membros que se constituiriam em um perfil determinado de atuação. Elas tratariam a sociedade brasileira como hipossuficiente em sua ação política e qualificariam as instituições representativas como insatisfatórias pela não concretização de políticas públicas e o pelo envolvimento de atores com atos de improbidade administrativa. Para o autor, o voluntarismo político dos membros do Ministério Público possui um valor negativo tanto por se aproximar de uma corrente autoritária do pensamento político brasileiro quanto por ser composto por práticas institucionais que caracterizam um movimento de substituição do sistema político pelo judicial na resolução de conflitos e de protagonismo do Ministério Público em detrimento da sociedade.

Em contraste com a visão anterior, a segunda perspectiva de interpretação é encontrada nos trabalhos organizados por Luiz Werneck Vianna, os quais consideram a interação entre o Ministério 
Público e a sociedade civil como transformadora da realidade social, uma vez que possibilitaria mais uma importante forma de participação na vida pública via sistema de justiça, além do controle dos poderes delegados. Em sua análise, o Ministério Público é mostrado como um lócus do exercício de uma "soberania complexa", a qual abrange não somente as formas de representação vinculadas ao sistema políticorepresentativo, mas também a representação funcional e as dimensões da cidadania social. Em oposição ao trabalho anterior, sua pesquisa traz dados empíricos sobre o uso crescente dos instrumentos judiciais pelos diversos agentes sociais e políticos (VIANNA et al., 1999; VIANNA, BURGOS, 2002).

Maciel (2002) inaugura uma terceira linha interpretativa a respeito do perfil de atuação do Ministério Público, que propõe a necessidade de trabalhos mais aprofundados sobre as formas de interação que a instituição estabelece com a sociedade civil e seus resultados. Sua tese mostra a importância do estudo da relação entre fatores externos, oriundos de interesses e valores de uma sociedade imersa em um contexto de expansão de novos direitos, e fatores endógenos visualizados na tensão entre os diferentes projetos de ação institucional e os mecanismos organizacionais internos.

Em relação a tais mecanismos, a autora aborda dois recursos organizacionais centrais utilizados para racionalizar as atividades dos membros da instituição em conflitos ambientais. O primeiro tem caráter estratégico e envolve as políticas institucionais de orientação e coordenação das ações individuais dos seus membros, a exemplo das promotorias estaduais especializadas, dos centros de apoio operacional e dos planos e programas de atuação. O segundo tipo refere-se a mecanismos responsáveis pela rotinização das práticas profissionais dos seus integrantes, os quais resultam em um caráter individualizante de atuação e acabam por dificultar as estratégias 
coordenadas de atuação tanto no âmbito interno como com agentes externos.

Antes de tratarmos desses recursos organizacionais no objeto da pesquisa, é importante trazer o desenvolvimento das novas regras institucionais balizadoras do papel do MPT. A Constituição Federal de 1988 conferiu nova institucionalidade ao Ministério Público da União (MPU), atribuindo-lhe independência dos Poderes e a defesa da sociedade. Contudo, dentro da singularidade de um ramo especializado do direito, os procuradores do trabalho tiveram que enfrentar o desafio externo de uma Justiça de Trabalho que se negava a julgar o mérito das ações civis públicas trabalhistas, de modo que foi apenas com o Estatuto do MPU, a Lei Complementar 75/93, que o MPT teve maior poder de intervir nas relações trabalhistas, uma vez que a lei explicitava suas atribuições (PRADO, 2015). Além disso, mesmo após essa lei, os obstáculos à procedimentalização das ações civis públicas trabalhistas permaneceram, de modo que, durante muitos anos, não foi reconhecida a legitimidade do MPT para defender direitos individuais homogêneos ${ }^{3}$. Outra resistência encontrada refere-se ao reconhecimento de danos morais coletivos.

O desafio interno à instituição explicitado nas entrevistas foi de promover uma ação no ambiente político, através de sua associação nacional, para que o MPT pudesse constituir-se como uma instituição propícia à atuação como agente, realizando mudanças organizacionais que se referem à dinâmica de escolha do Procurador-Geral do Trabalho e à criação das Coordenadorias Temáticas.

Os entrevistados entendem que o Procurador-Geral do Trabalho é uma liderança na instituição. Desse modo, apontaram para diferentes perfis de atuação da Procuradoria Geral do Trabalho ao longo da construção do papel de agente do MPT, ora estimulando uma

3 São direitos individualizáveis, mas coletivos na forma em que são defendidos juridicamente. Assim, esses direitos deixam de importar ao indivíduo apenas e passam a envolver uma questão coletiva. 
atuação mais coordenada dos projetos nacionais, ora atuando em temas pontuais. O trabalho de Maciel (2000) trata da importância do estudo dos sentidos que membros e lideranças institucionais conferem às suas novas atribuições jurídico-políticas e alerta para a coexistência de "perfis de atuação mais formalistas em oposição àqueles direcionados às ações de caráter deformalizador".

A mudança na escolha do Procurador-Geral do Trabalho foi apoiada por procuradores do trabalho que ocuparam posições na presidência da Associação Nacional de Procuradores do Trabalho (ANPT) e articulada nos espaços de discussão promovidos pela associação, especialmente o congresso jurídico e o encontro associativo que ocorrem anualmente, ${ }^{4}$ os quais foram utilizados para defender que o Procurador-Geral do Trabalho tivesse um perfil de atuação como agente, entendido pelos entrevistados como pautado no novo papel constitucional de defesa da sociedade.

A demanda por democratização na escolha da cúpula encontrou uma resposta positiva, pela primeira vez, no cenário político de 2003, quando o Procurador-Geral da República nomeado foi o mais votado da lista tríplice do Ministério Público Federal ${ }^{5}$. Aproveitandose dessa conjuntura, segundo informações de uma entrevistada ${ }^{6}$, a ANPT teria feito um contato com o novo Procurador-Geral da República para explicar o motivo pelo qual, dentro da lista tríplice do $\mathrm{MPT}$, os nomes não eram de procuradores do último grau de carreira,

4 Para um estudo do processo de redefinição de papéis via associações corporativas de juristas em torno das interpretações legítimas da Constituição de 1988, ver Engelmann (2006).

5 A escolha da cúpula das instituições é sem dúvida um tema importante na discussão do controle das instituições judiciais. A nomeação do Procurador Geral da República pelo Chefe do Poder Executivo Federal dá-se após indicação de seu nome e aprovação pelo Senado. Assim, independe da formação de uma lista tríplice pela categoria, mas, desde 2003, a Presidência tem nomeado o mais votado da lista.

6 Os dados também são encontrados no livro Jornada de Trabalho: histórias do MPT (2015) ao qual tivemos acesso pela nossa participação como público externo no Simpósio "Jornada Histórica do MPT - nos 30 anos da Lei da Ação Civil Pública", ocorrido de 1 a 2 de julho de 2015. 
o que tradicionalmente ocorria dentro do Ministério Público, mas de procuradores que tinham experiência na atuação como agente. Além disso, a pedido do novo Procurador-Geral da República, a associação teria promovido um debate entre os candidatos, com ampla participação dos procuradores do trabalho. Nesse debate, candidatos contrários à nomeação de alguém que não fosse do último grau de carreira (Subprocurador- Geral) teriam se recusado a participar.

Como resultado desse processo, pela primeira vez, foi nomeada uma procuradora regional, compondo a lista tríplice como a mais votada pelos membros da instituição. Em sua gestão (2003-2007), além de afirmar as coordenadorias já existentes - a Conaete (Coordenadoria Nacional de Erradicação do Trabalho Escravo), a Coordinfância (Coordenadoria Nacional de Combate à Exploração do Trabalho da Criança e do Adolescente) e a Coordigualdade (Coordenadoria Nacional de Promoção de Igualdade de Oportunidades e Eliminação da Discriminação no Trabalho) - após consulta ao colégio de procuradores, que é formado por todos seus membros, promoveu a criação das coordenadorias nacionais: a Conafret (Coordenadoria Nacional de Combate às Fraudes nas Relações de Trabalho), Conap (Coordenadoria Nacional de Combate às Irregularidades Trabalhistas na Administração Pública); Codemat (Coordenadoria Nacional de Defesa do Meio Ambiente do Trabalho) e a Conatpa (Coordenadoria Nacional de Trabalho Portuário e Aquaviário) ${ }^{7}$.

Compostas por um coordenador nacional e seu vice, além de um representante em cada regional, as coordenadorias nacionais desenvolvem os projetos nacionais do MPT. São formas organizacionais que visam priorizar a atuação de agente dentro da instituição a partir de objetivos traçados coletivamente. ${ }^{8}$

7 Por fim, em 2009, foi criada a Coordenadoria Nacional de Promoção da Liberdade Sindical. Segundo entrevistado, essa foi a última coordenadoria criada devido à ausência de consenso entre os membros sobre o papel da mesma.

8 No entender de um entrevistado, as coordenadorias não seriam meros lócus de reunião 
Parajustificar a atuação das coordenadorias dentro da estrutura institucional do Ministério Público, os entrevistados defenderam que o princípio da independência funcional deve ser lido à luz do princípio da unidade ${ }^{9}$. O princípio da independência funcional é visto tanto como uma garantia de uma atuação livre de ingerências arbitrárias como um ideal orientador de uma atuação inovadora, baseada em princípios constitucionais, que pode vir pautar a instituição. Já o princípio da unidade possibilitaria a coordenação das ações institucionais e a definição de estratégias para se atingirem as metas prioritárias. Apesar dos entrevistados valorizarem positivamente a atuação baseada em princípios constitucionais e direcionada para projetos nacionais ou regionais, entendem que esse modelo existe em contraposição a um perfil predominante, que atua com base estritamente na lei e em denúncias individuais.

\section{A Legitimidade das Opções Procedimentais de Atuação do MPT}

As pesquisas empíricas vêm destacando a preferência dos membros do MP pelo uso de métodos extrajudiciais em relação aos métodos judiciais (MACIEL, 2000, 2002; SOARES, 2007). Mas, ao contrário de uma simples substituição da sociedade e mesmo do Judiciário, na visão de Vianna e Burgos (2002), o MP reuniria esforços da própria instituição, de outros agentes estatais e da sociedade civil para a o cumprimento dos direitos.

Nesse sentido, Maciel (2000) reconhece as implicações democratizantes de uma política institucional voltada a um modelo consensual de resolução de conflitos, considerando a celeridade e eficácia das soluções, a redução de impasses envolvidos na decisão

de especialistas, como em outros ramos do Ministério Público, mas, através de discussões, chegariam a entendimentos uniformes sobre como atuar, os quais são materializados em suas orientações.

9 Ideia presente nas entrevistas e no material organizado pelo MPT sobre as coordenarias temáticas (PEREIRA, 2006). 
judicial e a diminuição das distâncias entre a esfera formal e os cidadãos. No entanto, a autora aborda as dificuldades enfrentadas para a generalização de experiências baseadas nesse modelo, presentes nos obstáculos legais, na diversidade de atores e interesses envolvidos e na complexidade para a consolidação de uma identidade institucional devido à liberdade de atuação individual garantida pela autonomia funcional.

O último balanço da atuação do Ministério Público no ano de 2014 (CNMP, 2015) mostra que a maior parte das questões trazidas ao MPT é resolvida no âmbito extrajudicial, por meio dos TACs. Em relação à atuação do MPT, essas questões, em sua maioria, referemse ao descumprimento de direitos trabalhistas contratuais, dentro do qual a não assinatura de carteira de trabalho é um exemplo. Os dados disponíveis sobre as áreas temáticas das coordenadorias objeto deste estudo partem do ano 2013. Ainda que, no ano de 2015, se note um decréscimo em algumas áreas, os dados gerais sistematizados também apontam para um aumento das ações judiciais.

Quadro 1 - TACS e Petições Iniciais em Áreas temáticas

\begin{tabular}{|c|c|c|c|c|c|}
\hline TACs & $\begin{array}{c}\text { Trabalho } \\
\text { infantil }\end{array}$ & $\begin{array}{c}\text { Trabalho } \\
\text { escravo }\end{array}$ & Igualdade & $\begin{array}{c}\text { Fraudes } \\
\text { Trabalhistas }\end{array}$ & $\begin{array}{c}\text { Meio } \\
\text { ambiente }\end{array}$ \\
\hline 2013 & 1824 & 305 & 965 & 1225 & 4342 \\
\hline 2014 & 1787 & 388 & 996 & 1229 & 4501 \\
\hline 2015 & 1373 & 314 & 856 & 903 & 3916 \\
\hline $\begin{array}{c}\text { Petições } \\
\text { iniciais }\end{array}$ & $\begin{array}{c}\text { Trabalho } \\
\text { infantil }\end{array}$ & $\begin{array}{c}\text { Trabalho } \\
\text { Escravo }\end{array}$ & Igualdade & $\begin{array}{c}\text { Fraudes } \\
\text { Trabalhistas }\end{array}$ & $\begin{array}{c}\text { Meio } \\
\text { ambiente }\end{array}$ \\
\hline 2013 & 171 & 67 & 286 & 417 & 924 \\
\hline 2014 & 534 & 299 & 906 & 1351 & 3477 \\
\hline 2015 & 471 & 243 & 894 & 2266 & 3127 \\
\hline
\end{tabular}

Fonte: Dados publicados nos retratos do Ministério Público $(2014 ; 2015)$ para os anos de 2013 e 2014 e dados fornecidos, pela Corregedoria Geral do MPT, em maio de 2016, para o ano de 2015. 
Os obstáculos formais para efetivação dos direitos pela via judicial são apresentados como um dos argumentos da legitimidade do uso do TAC, que ofereceria uma resposta mais célere para a sociedade. Os entrevistados justificaram o uso dos TACS afirmando que não se trata de transacionar direitos que são da sociedade, mas de negociar a forma de cumprimento das obrigações, visando-se obter um título executivo de modo mais rápido que a sentença judicial. Como critério para não firmar o TAC, apontam a posição da parte denunciada de não mostrar o propósito de cumpri-lo somada à percepção, pelo procurador, de que o mesmo não vai garantir a ordem jurídica, ou seja, não vai inibir o desrespeito aos direitos.

Segundo as entrevistas, o uso dos TACs é mais aceito em determinadas áreas do que em outras. Em matérias nas quais se faz necessária uma discussão com a sociedade e o poder público para combater as causas do problema, a exemplo da área de trabalho infantil, são propostos termos de ajuste de conduta. Em áreas como meio ambiente do trabalho, são preferidos os TACs para que a causa que está comprometendo a saúde e segurança seja eliminada mais rapidamente. Mas, em áreas como fraudes, prefere-se ajuizar uma ação.

O limite das negociações é, contudo, uma questão em disputa, com entrevistados criticando a postura daqueles outros procuradores que fazem TACs abrindo mão da garantia da ordem jurídica. Essa questão aparece na literatura em algumas pesquisas sobre o MPT lideradas por Filgueiras (2012), que defende que o TAC é um instrumento de conciliação entre o MPT e a empresa infratora. Com base em um banco de dados por ele construído, o autor afirma que a inexistência de danos morais no conjunto de TACs analisados, a possibilidade de flexibilização no cumprimento de multas e a não fiscalização do cumprimento dos TACs corroboram essa afirmação. Tem-se, portanto, que esse tipo de atuação dentro do MPT aproxima- 
se das ações do Ministério Público em conflitos ambientais descritas pela pesquisa empírica de Soares (2007), que se distanciariam da missão constitucional ao permitirem o descumprimento da legislação sem estabelecer um "compartilhamento de responsabilidades" entre Ministério Público, agentes estatais e entes da sociedade civil, tal como proposto por Vianna e Burgos. Neste tipo de atuação, contrariamente aos autores citados, a instituição não estaria funcionando "como uma instância que agrega esforços, visando construir uma base institucional para o cumprimento do direito." (VIANNA; BURGOS, 2002, p. 444).

Essas críticas são conhecidas pelos entrevistados que afirmaram que os TACs são por eles fiscalizados, mas que não há uma política institucional de acompanhamento da sua fiscalização. Porém, entendem que o número das ações civis públicas tem aumentado e que o pagamento por danos morais coletivos tem sido firmado inclusive nos TACs, de forma que isso pode ser um indicativo de um controle institucional desses instrumentos. Nesse sentido, entendemos que a reação das empresas com a finalidade de não assinar TACs pode ser vista como um resultado do aumento dos valores propostos por danos morais coletivos, dentro de uma estratégia para postergar o cumprimento de obrigações, preferindo enfrentar uma ação judicial. ${ }^{10}$

Conforme observado por Maciel (2000), o tema da legitimidade social e política e da consolidação institucional do Ministério Público está associado às opções procedimentais. No caso do MPT, isso tem implicado na prática de pedir o dano moral coletivo nas ações civis públicas ${ }^{11}$ para depois estendê-lo aos TACs. Segundo os entrevistados, o reconhecimento da existência do dano moral coletivo pela Justiça

10 Subprocuradores do Trabalho entrevistados afirmaram que a assinatura dos TACS pelas empresas já não tem ocorrido com facilidade. Artigo publicado pelo Valor Econômico mostra essa tensão ao sugerir que o TAC poderia "virar peça de museu" se o MPT não negociasse as cláusulas nas quais a empresa se compromete a deixar terceirizar. (ANDRADE, 2014).

11 A coordenadoria nacional que atua no combate ao trabalho escravo tem uma orientação expressa nesse sentido. Segundo desembargadora do TRT-RJ, este é um pedido comum nas ações civis públicas do MPT. 
do Trabalho foi um processo lento, baseado na estratégia dos procuradores do trabalho, que começaram pedindo valores ínfimos para que a instituição aceitasse a existência do dano moral coletivo e, a partir daí, os valores foram sendo elevados. O dano moral coletivo é apresentado pelos procuradores do trabalho com uma função pedagógica de dar exemplo para que as demais empresas cumpram a legislação; uma função punitiva para o transgressor da ordem jurídica e uma função compensatória da sociedade pela lesão por meio de um valor destinado ao Fundo de Amparo ao Trabalhador ou a entidades que desenvolvem projetos e órgãos públicos que auxiliam o trabalho do MPT.

Em termos de aproximação com a sociedade civil, uma liderança da Comissão Pastoral da Terra (CPT) no combate ao trabalho escravo fez uma avaliação positiva da atuação do MPT, que teria avançado mais que outros ramos do MP porque "unificou procedimentos e definiu regras de atuação". Também descreveu um processo em que a CPT convenceu-se sobre a legitimidade dos TACs. Tal convencimento teve por base os argumentos jurídicos do reconhecimento de culpa por parte do infrator que firmava o TAC e da existência de uma obrigação de pagar por dano moral coletivo, elementos que lhe pareceram interessantes comparativamente à dificuldade de serem conseguidas condenações na Justiça Penal. Além disso, para o entrevistado, a construção da legitimidade dos TACs também teria passado pelo reconhecimento da importância do trabalho da CPT pelos procuradores do trabalho, os quais participavam dos cursos de capacitação oferecidos pela organização e destinavam os valores de reparação do dano moral coletivo cometido para seus projetos, por exemplo, a construção de uma casa de refugiados e ações envolvendo a comunidade escolar de 25 municípios.

Além disso, a liderança avaliou positivamente quando Ruth Vilela (que tem longa trajetória na secretaria da fiscalização) organizou 
60 fiscalizações, aproximadamente em 2007, de empresas da lista suja do trabalho escravo para ver se havia reincidência. Essa interpretação da liderança sobre os limites do TAC está de acordo com a visão dos procuradores do trabalho que defendem que o instrumento deve ser utilizado dentro de um modelo de projetos em parceria com outras instituições e atores para que se tenha a efetividade desejada. No mesmo sentido, os procuradores do trabalho defenderam que o problema a ser enfrentado não está no uso dos TACs, mas no modelo de atuação baseado principalmente em denúncias individuais, o qual prejudicaria o modelo de atuação baseado em ações coordenadas. Nesse último, a efetivação de direitos dependeria da atuação conjunta entre o MPT e uma rede institucional.

Um olhar centrado na organização interna mostra que colaboram para a manutenção de um perfil individualizador de atuação não apenas o caráter rígido da avaliação da atuação dos procuradores de trabalho pelo Conselho Nacional do Ministério Público, o qual é baseado em números de procedimentos realizados e não em projetos desenvolvidos, mas também a inexistência de incentivos formais à atuação coordenada, uma vez que os membros das coordenadorias continuam a responder a todo tipo de demandas.

Contudo, esse caráter rotinizador não impede que o MPT participe de diversos fóruns e que se utilize de expedientes promocionais, chamados de "promo". Esses expedientes contam com a participação de organismos privados e públicos visando à identificação de problemas e à proposta de formas preventivas ou de soluções via políticas públicas. Como exemplo de uso desses instrumentos temse as ações de combate ao trabalho infantil pelas quais os municípios são questionados a apresentar informações e estratégias a fim de que sejam realizadas gestões voltadas à implementação de programas de profissionalização ${ }^{12}$. OMPT possui um banco de dados digital que pode

12 A orientação COORDINFÂNCIA n. 4 estabelece que "É competente a Justiça do Trabalho 
colaborar na ação estratégica, mas os dados não estão abertos. Pela corregedoria, tivemos acesso aos "promo" em duas áreas temáticas. $\mathrm{Na}$ área de combate ao trabalho infantil, em que há um direcionamento para seu uso, em 2013, 2014 e 2015 foram realizados, respectivamente, 266, 128 e 56 "promos" no país. Em meio ambiente do trabalho, foram realizados nos anos citados, 97, 104 e 68 ações promocionais. Segundo informações de um Subprocurador-Geral do Trabalho, inicia-se uma discussão sobre a regulamentação dos mesmos para que possam ser contabilizados os resultados sobre esse tipo de atuação, que não aparece nos relatórios do MP, para que haja estímulos para uma ação coordenada por meio dos mesmos. Assim, esse instrumento que visa à coordenação de redes institucionais promotoras de políticas públicas ainda não está consolidado e sua utilização vem decrescendo, conforme apontam os dados.

\section{A Formação da Agenda do MPT}

Nos trabalhos a respeito da definição de agenda política estão presentes os estudos dos atores, mecanismos, processos e contextos específicos que podem levar os assuntos públicos às arenas públicas (ARARAL JUNIOR, 2013). Por sua vez, a formação da agenda em instituições judiciais tem sido estudada a partir de diferentes perspectivas, as quais são focadas nos tribunais, na relação das Cortes com os outros Poderes, e na interação do Poder Judiciário com a sociedade. O modelo estratégico tem-se aberto ao estudo dos contextos

para processar e julgar ações civis públicas que tenham como objeto a imputação de obrigações ao Poder Público, relativamente à criação e implementação de políticas públicas para prevenção e erradicação do trabalho infantil, nos termos do art. 114, I da CF/88". O tema está em discussão na Justiça do Trabalho, o que mostra a importância do estudo dos obstáculos formais para o desenvolvimento do papel de agente do MPT em cooperação com atores e instituições externos. A Segunda Turma do TST decidiu que a Justiça do Trabalho tem competência para julgar ação civil pública em que o MPT requer a condenação do Município de Chapadinha (MA) para que implemente políticas públicas com o objetivo de erradicar e prevenir o trabalho infantil (BAHIA, 2015). 
institucionais específicos em que os juízes atuam para alcançar seus objetivos. Tais objetivos não são apenas particulares, mas também se referem às normas mais gerais que estruturam o comportamento, por exemplo, como é concebida a função do Poder Judiciário no sistema constitucional, além de regras decisórias e de acesso às Cortes e dos valores presentes na sociedade (INATOMI, 2016).

Nas abordagens do institucionalismo histórico (GILLMAN, 1999, 2004) e da mobilização do direito (MCCANN, 1994, 1996, 2008, 2010), a política judicial é tratada do ponto de vista de suas interações com outros agentes inseridos em seu contexto político, econômico e social. Nesse sentido, os trabalhos de Koerner (2007, 2012, 2013) têm apresentado que as normas jurídicas não estão simplesmente à disposição de seus membros, mas sua utilização envolve a tradução sob a forma de elementos jurídicos da estruturação social do direito, nos quais estão presentes as ideias jurídicas historicamente construídas, as relações estratégicas e as interações com os demais agentes políticos e sociais.

A formação da agenda do MPT deu-se dentro de um cenário em que problemas sociais foram sendo redefinidos como questão de direitos humanos. Nesse cenário, a internacionalização das mudanças culturais e econômicas revelou não apenas a vulnerabilidade a que certos grupos estavam sujeitos, mas também as disputas em torno da interpretação das normas que poderiam conferir novos significados aos direitos e à sua efetivação. A construção das novas coordenadorias e afirmação das existentes é fruto de um consenso entre os procuradores do trabalho sobre as metas da instituição e de um trabalho anterior à sua criação a partir da atuação de seus membros seja em temas alinhados com a Organização Internacional do Trabalho (OIT) - combate ao trabalho escravo, ao trabalho infantil e à discriminação- seja na defesa de princípios da ordem jurídica trabalhista como o combate às fraudes e na afirmação de direitos estabelecidos pela Constituição Federal 
de 1988 dentro de um arranjo de políticas públicas, por exemplo, de defesa do direito ao meio ambiente, incluindo o do trabalho.

Impulsionada por procuradores do trabalho de determinadas regiões e transformada em coordenadoria ${ }^{13}$, o combate às fraudes é uma das áreas que mais movimenta a atuação extrajudicial e judicial do MPT. Segundo o trabalho de Carelli; Casagrande e Périssé (2007, p. 63) sobre as ações civis públicas promovidas no Rio de Janeiro de 1992 a 2003, praticamente metade de todas as ações sobre fraude à relação de emprego foram ajuizadas a partir de procedimentos instaurados de ofício pelo MPT. O papel ativo do MPT nessa área é entendido pelos entrevistados como defesa da ordem jurídica, esperando-se que o procurador do trabalho não faça acordos que a comprometam. Assim, entendem que muito mais importante que a defesa de interesses é a defesa de princípios que orientam para a não aceitação de qualquer tipo de fraude à ordem trabalhista. Como exemplos desse tipo de atuação estão as ações de combate às falsas cooperativas e à terceirização ilícita. Segundo os entrevistados, além de resolver as demandas, ao agir com base no princípio de defesa da ordem jurídica, sinaliza-se às empresas e ao poder público que não terão êxito ao empregarem formas de burlar os direitos trabalhistas, o que pode resultar em conflitos com esses agentes. ${ }^{14}$

A cooperação do MPT com atores sociais está mais fortemente associadaaocombateaotrabalhoescravonoBrasil, queentrounaagenda institucional das políticas públicas a partir de pressões de organismos

13 Segundo entrevistado, a Coordenadoria Nacional de Combate às Fraudes nas Relações de Trabalho foi criada a partir de dois centos de combate às falsas cooperativas e à terceirização irregular - Campinas e Rio de Janeiro, sendo que Campinas foi o pioneiro.

14 Um exemplo dessas ideias está em uma ação civil pública sobre o selo da cana. Em 2009, foi lançado o "Compromisso Nacional para Aperfeiçoar as Condições de Trabalho na Cana-deaçúcar", que envolve a concessão do selo de empresa compromissada. Conforme narrou um procurador do trabalho do interior de São Paulo, o selo foi usado instrumentalmente para afastar a fiscalização feita por funcionários públicos, a qual é determinada na convenção 81 da OIT, determinando-a a entidades privadas. Em abril de 2013, houve a extinção do compromisso nacional da cana. 
internacionais, após denúncias dos movimentos sociais. A atuação do MPT dá-se nos grupos móveis de fiscalização, além da participação na Comissão Nacional para Erradicação do Trabalho Escravo (e mesmo nas estaduais, onde elas existem) e por meio da Coordenadoria Nacional de Erradicação do Trabalho Escravo (CONAETE), criada pela instituição em 2002. As orientações da CONAETE que norteiam a atuação dos procuradores do trabalho enfatizam a ampliação do conceito de trabalho escravo trazida pela inovação no Código Penal, associando-o ao desrespeito à dignidade humana ${ }^{15}$. Atualmente, o MPT e demais instituições e atores mobilizados enfrentam o Projeto de Lei do Senado 432, de 2013, que restringe o conceito de trabalho escravo àquele sob ameaça de punição, com uso de coação ou com restrição da liberdade pessoal, além de retenção no local de trabalho, vigilância ostensiva, apropriação de documentos do trabalhador e restrição da locomoção em razão de dívida contraída com o empregador ou representante.

Por meio da CONAETE, o MPT desenvolve projetos nacionais, em atividades econômicas específicas levantadas a partir de denúncias recorrentes, por exemplo, em usinas de cana de açúcar, na extração da carnaúba, na construção civil, em frigoríficos e oficinas de costura. A atual vice-coordenadora da CONAETE entende que a posição do Poder Judiciário em relação ao reconhecimento do trabalho escravo melhorou nos últimos anos, mas que ainda depende do tribunal e do juiz. Analisando que a questão está em plena disputa, informa uma atuação estratégica dos procuradores do trabalho baseada em

15 A Orientação CONAETE n. 3 determina que as "condições degradantes de trabalho são as que configuram desprezo à dignidade da pessoa humana, pelo descumprimento dos direitos fundamentais do trabalhador, em especial os referentes à higiene, saúde, segurança, moradia, repouso, alimentação ou outros relacionados a direitos da personalidade, decorrentes de situação de sujeição que, por qualquer razão, torne irrelevante a vontade do trabalhador." Já a Orientação CONAETE n. 4 define que "Jornada de trabalho exaustiva é a que, por circunstâncias de intensidade, frequência, desgaste ou outras, cause prejuízos à saúde física ou mental do trabalhador, agredindo sua dignidade, e decorra de situação de sujeição que, por qualquer razão, torne irrelevante a sua vontade." (BRASIL, 2009, p. 31). 
critérios objetivos para caracterizar as condições degradantes no trabalho rural e urbano, por exemplo, a ausência de equipamento de proteção individual e alojamentos em péssimas condições, como currais ou espaços de trabalho com fiações expostas e sem rota de fuga. Outra estratégia dos procuradores do trabalho é a de utilizarem teorias que demonstram a subordinação estrutural para avançar na responsabilização da cadeia produtiva.

A OIT tem apresentado o Brasil como uma liderança na atenção a formas de exploração do trabalho que podem deixar grupos vulneráveis sem o direito à dignidade e que, embora baseadas em suas convenções, incluem a noção de condições degradantes (OIT, 2009). Por meio da participação nas discussões sobre a adoção de um protocolo adicional à Convenção 29 da OIT e a uma Recomendação, os procuradores do trabalho têm apresentado a OIT como um espaço de mobilização contra "qualquer nova definição para trabalho forçado ou obrigatório que representasse retrocesso em relação aos conceitos de nossa legislação doméstica" e de "internacionalização de teorias e práticas brasileiras em matéria de combate ao trabalho escravo", dentre elas a responsabilidade por trabalho escravo em cadeia produtiva (MELO et al., 2015, p. 311).

A partir de uma análise bottom-up, a abordagem da mobilização do direito relativiza o que pode ser visto como uma mudança social através das instituições judiciais ao considerar que a sua ativação (e não necessariamente o seu resultado) pode impulsionar outras lutas em outras arenas públicas (McCANN, 1994). Essas ações em diferentes arenas têm servido para organizar os atores, aumentar sua participação e promover ações estratégicas com outros grupos, de modo a expandir recursos e desenvolver táticas.

Nesse sentido, no tema do trabalho escravo, a interação entre MPT e setores da sociedade civil tem envolvido não apenas procedimentos judiciais e extrajudiciais, mas também a participação 
na formulação e implementação de políticas públicas, além da atuação política no Congresso Nacional, especialmente nas demandas pelo estabelecimento e pela manutenção da legislação que traz o conceito de trabalho escravo como aquele realizado em condições degradantes e em desrespeito à dignidade humana.

Quadro 2 - Medidas institucionais de combate ao trabalho Escravo

\begin{tabular}{|c|c|c|}
\hline Decreto de 31.07. 2003. & $\begin{array}{l}\text { Após denúncias que } \\
\text { levaram o Brasil à Comissão } \\
\text { Interamericana de Direitos } \\
\text { Humanos da Organização dos } \\
\text { Estados Americanos, firmou- } \\
\text { se um acordo com o escopo } \\
\text { de uma mudança da política } \\
\text { no país. Nesse contexto, } \\
\text { houve a criação da Comissão } \\
\text { nacional para erradicação do } \\
\text { trabalho escravo (CONATRAE) }\end{array}$ & $\begin{array}{c}\text { Planos Nacionais de } \\
\text { prevenção e erradicação } \\
\text { do trabalho escravo }\end{array}$ \\
\hline $\begin{array}{l}\text { Portaria MTE n. 540, de } 19 \text { de } \\
\text { outubro de 2004, atualizada } \\
\text { pela Portaria Interministerial } \\
\text { MTE e Secretaria de } \\
\text { Direitos Humanos n.2, de } \\
\text { 2011, e substituída pela } \\
\text { Portaria Interministerial } \\
\text { MTE/ SEDH e Secretaria de } \\
\text { Direitos Humanos n.2, DOU } \\
\text { 01.04.2015 }\end{array}$ & $\begin{array}{l}\text { Organizam o Cadastro de } \\
\text { Empregadores que tenham } \\
\text { mantido trabalhadores em } \\
\text { condições análogas a de } \\
\text { escravo, desestimulando } \\
\text { o patrocínio de entidades } \\
\text { públicas e privadas nesses } \\
\text { investimentos }\end{array}$ & $\begin{array}{c}\text { Em liminar, na } \\
\text { Ação Direta de } \\
\text { Inconstitucionalidade } \\
\text { n. 5209/DF, o STF } \\
\text { proibiu sua publicação. } \\
\text { O governo edita nova } \\
\text { portaria, baseada na Lei } \\
\text { de Informações e em } \\
\text { convenções da OIT }\end{array}$ \\
\hline $\begin{array}{c}\text { Portaria PGT no 231, de } 12 \text { de } \\
\text { setembro de } 2002\end{array}$ & $\begin{array}{l}\text { O MPT cria a Coordenadoria } \\
\text { Nacional de Erradicação do } \\
\text { Trabalho Escravo (CONAETE) }\end{array}$ & $\begin{array}{l}\text { Estabelecimento de uma } \\
\text { política institucional } \\
\text { do MPT para o tema, } \\
\text { por meio de ações civis } \\
\text { públicas e dano moral } \\
\text { coletivo }\end{array}$ \\
\hline
\end{tabular}




\begin{tabular}{|c|c|c|}
\hline Lei $10.803 / 2003$ & $\begin{array}{c}\text { Altera o art. } 149 \text { do Código } \\
\text { Penal }\end{array}$ & $\begin{array}{l}\text { Trabalho escravo } \\
\text { típico: (1) trabalho } \\
\text { forçado ou em (2) } \\
\text { jornada exaustiva; (3) } \\
\text { trabalho em condições } \\
\text { degradantes; e (4) } \\
\text { trabalho com restrição } \\
\text { de locomoção, em razão } \\
\text { de dívida contraída. } \\
\text { Trabalho forçado por } \\
\text { equiparação: retenção } \\
\text { no local de trabalho, } \\
\text { (1) por cerceamento } \\
\text { do uso de qualquer } \\
\text { meio de transporte; } \\
\text { (2) por manutenção } \\
\text { de vigilância ostensiva; } \\
\text { ou (3) por retenção de } \\
\text { documentos ou objetos } \\
\text { de uso pessoal do } \\
\text { trabalhador. }\end{array}$ \\
\hline $\begin{array}{l}\text { Lei } \mathrm{n} .10 .608 \text {, de } 20 \text { de } \\
\text { dezembro de } 2002\end{array}$ & $\begin{array}{l}\text { Altera a Lei n. } 7.998, \text { de } 11 \\
\text { de janeiro de } 1990\end{array}$ & $\begin{array}{c}\text { Concede Seguro- } \\
\text { Desemprego para o } \\
\text { trabalhador resgatado } \\
\text { da condição análoga à } \\
\text { de escravo }\end{array}$ \\
\hline $\begin{array}{c}\text { Emenda Constitucional 81, de } \\
\text { junho de } 2015 .\end{array}$ & $\begin{array}{l}\text { Dá nova redação ao art. } 243 \\
\text { da Constituição Federal. }\end{array}$ & $\begin{array}{l}\text { Expropriação das } \\
\text { propriedades rurais e } \\
\text { urbanas com exploração } \\
\text { de trabalho escravo na } \\
\text { forma da lei. O projeto } \\
\text { de Lei do Senado } \\
\text { 432, de } 2013 \text {, visa } \\
\text { regulamentá-la com } \\
\text { um conceito restrito de } \\
\text { trabalho escravo. }\end{array}$ \\
\hline
\end{tabular}

Fonte: Elaboração própria.

Outro exemplo de cooperação com agentes externos à instituição e que está relacionada com as normativas e o apoio da OIT é o da igualdade. Além do temário específico da Coordigualdade, 
dentro do qual há, por exemplo, a proibição de revistas íntimas, outros três projetos estão em curso: a inclusão de deficientes no mercado de trabalho; contra o assédio moral e o Programa de Promoção da Igualdade de Oportunidades para Todos (PIOPT). Demandado pelo movimento negro e pela OIT, o PIOPT foi liderado pelo ProcuradorGeral do Trabalho Otávio Lopes com objetivo de combater a discriminação racial e de gênero, que ocorre na admissão, na remuneração e na ascensão na carreira. Para iniciá-lo, em 2005, o MPT se valeu de informações discutidas em oficina feita em conjunto com OIT, envolvendo o IPEA, o MTE, o IBGE, o DIEESE e outras entidades e atores. Tais informações fornecem mapas de segmentos econômicos que apresentam desigualdades de gênero e raça recorrentes. Com base nesses mapas, há a notificação das empresas para fornecimento de esclarecimentos sobre o quadro de pessoal. Posteriormente, há a realização de termos de ajuste de conduta ou ações civis públicas para combater as desigualdades encontradas. O primeiro setor escolhido para a instauração do programa foi o bancário. Segundo Conceição (2013, p. 185), apesar da resistência dos magistrados em se reconhecer a discriminação indireta, o MPT continuou negociando com a Federação Brasileira de Bancos. Esse projeto possivelmente aproximou os sindicatos dos bancários e o MPT na mobilização contra o assédio moral $^{16}$.

Além dessas atuações que têm seu espaço de mobilização e seus argumentos pautados na OIT, outras começaram pela ação política da sociedade civil mobilizada e são centradas nos arranjos de direitos e de políticas públicas da Constituição Federal de 1988, como as regras sobre o meio ambiente do trabalho. Um exemplo de cooperação com agentes sociais e estatais nessa questão foi a criação da “Comissão Temática destinada a estabelecer em saúde e segurança do

16 Este é um dado que estamos desenvolvendo em pesquisa coletiva coordenada pela Profa. Elina Pessanha, do PPGSA/IFCS/UFRJ. 
trabalhador", transformada na Coordenadoria Nacional de Defesa do Meio Ambiente do Trabalho (CODEMAT), que teve como inspiração para a articulação estratégica o Fórum Pernambucano de Combate aos Efeitos dos Agrotóxicos na Saúde do Trabalhador, no Meio Ambiente e na Sociedade (JARDIM; LIRA, 2013).

A criação da CODEMAT, em 2003, visou harmonizar as ações desenvolvidas pelo MPT na área e estimular a criação de Fóruns Estaduais de Proteção ao Meio Ambiente do Trabalho. Essa coordenadoria tem atuado por meio de cinco projetos nacionais relacionados ao banimento do amianto, à regularização das condições de trabalho no setor frigorífico, à regularização das condições de trabalho na cana de açúcar e à regularização das condições de trabalho na construção civil. No entanto, Artur (2014) constatou que existe um cenário de dificuldade da efetivação da Política Nacional de Saúde do Trabalhador e da Trabalhadora, pois o controle social em saúde do trabalhador não está consolidado no país. As exceções encontradas no Rio Grande do Norte e no Rio Grande do Sul contam com a participação do MPT, a qual é vista positivamente pelos atores sociais envolvidos. Tem-se, portanto, que a dinâmica de cooperação não é uniforme no país e está sujeita à superação de obstáculos formais e das rotinas individualizadoras da atuação.

Em relação ao Poder Judiciário, a edição da Súmula 736, em 2003, trouxe para a Justiça do Trabalho as questões relativas ao meio ambiente do trabalho e, assim, para o MPT, as atribuições para a investigação e ajuizamento dessas ações coletivas. Anos mais tarde, em 2009, por meio da atuação da ANAMATRA junto ao STF, a Súmula Vinculante 22 determinou que a competência da Justiça do Trabalho para processar e julgar as ações de indenização por danos morais e patrimoniais decorrentes de acidente de trabalho propostas por empregado contra empregador. Essas mudanças institucionais de competência, além do desenvolvimento de uma jurisprudência 
positiva em determinadas matérias relacionadas ao meio ambiente do trabalho ${ }^{17}$, têm estimulado a atuação dos procuradores do trabalho na área, inclusive indo além do formalismo, para abarcar também os servidores estatutários ${ }^{18}$. O meio ambiente do trabalho vem ganhando destaque dentro da instituição (ver quadro 1). Segundo um excoordenador da CODEMAT, se antes a coordenadoria era vista como uma área de difícil atuação por depender de um conhecimento para além da CLT e exigir inspeções, hoje se apresenta como uma área com mais procuradores atuantes inclusive pela maior resposta do Judiciário.

As dificuldades referentes aos aspectos individualizadores da atuação do MPT e a importância da valorização da atuação em políticas públicas começaram a ser debatidas pela instituição (ESPMU, 2015). Os entrevistados enfatizaram que o trabalho voltado para denúncias individuais prejudica as ações estratégicas direcionadas para políticas públicas, mas que resultados positivos dentro da atuação coordenada com agentes sociais e estatais são reconhecidos pelos pares e podem se tornar referências de atuação dos procuradores. Um exemplo é o resultado da atuação do procurador do trabalho, ex-coordenador da CODEMAT, que, após conseguir sentenças favoráveis contra empresas de transporte do DF que não seguiam normas de saúde e segurança do trabalho, e mesmo contra o governo do DF, passou a atuar em articulação com um fórum interinstitucional e conseguiu a

17 Como a aprovação pelo TST do Enunciado 438, que estendeu analogicamente o intervalo previsto no art. 253, da CLT, para os ambientes artificialmente frios, dentre outros temas em que o TST por meio da revisão de sua jurisprudência uniformizada tem ampliado a visão protetiva dos direitos do trabalhador no corte e plantio da cana-de açúcar (FREITAS, 2014).

18 “ADMINISTRAÇÃO PÚBLICA. ATUAÇÃO NA DEFESA DO MEIO AMBIENTE DO TRABALHO. O Ministério Público do Trabalho possui legitimidade para exigir o cumprimento, pela Administração Pública direta e indireta, das normas laborais relativas à higiene, segurança e saúde, inclusive quando previstas nas normas regulamentadoras do Ministério do Trabalho e Emprego, por se tratarem de direitos sociais dos servidores, ainda que exclusivamente estatutários (Orientação CODEMAT n. 7, em 2008)". A jurisprudência do STF tem oscilado sobre o tema (BRASIL, 2010). 
aprovação de um projeto de lei no DF estabelecendo que os motores nos ônibus sejam traseiros, evitando-se, assim, a perda auditiva dos trabalhadores.

\section{Considerações Finais}

A política institucional de desenvolvimento do papel do agente no MPT tem elementos endógenos e exógenos à instituição. Internamente, um grupo de procuradores do trabalho atuou a partir da ANPT para aproveitar a oportunidade de democratização da escolha do Procurador-Geral da República para promover a mudança visando à possibilidade do Procurador-Geral do Trabalho ser um procurador regional, posição na instituição que já teria permitido a experiência como agente. Neste cenário, os procuradores do trabalho conseguiram estabelecer uma mudança organizacional buscando a efetivação do papel de agente estabelecido pela Constituição de 1988, por meio das coordenadorias. Essa mudança coexiste com os obstáculos formais postos na Justiça do Trabalho e com um modelo que mede os resultados por atendimento a demandas individuais, e que não incentiva a participação em ações estratégicas e em formas de colaboração com agentes externos.

Externamente à instituição, a mobilização do direito realizada por atores sociais com o suporte de entidades como a OIT e dentro dos arranjos institucionais desenhados pela Constituição de 1988 contribuiu para a constituição do papel de agente do MPT. Este papel foi construído a partir de ações estratégicas e desenvolvido dentro de um modelo de permeabilidade a esse ambiente. Tal mobilização teve efeitos no próprio MPT, pois legitimou a sua atuação estratégica dentro da organização e fora dela, inclusive com a constituição de políticas públicas. 
Se considerarmos a combinação das perspectivas calculadora e cultural presentes no institucionalismo histórico (HALL; TAYLOR, 2003), o papel de agente do MPT tem sido construído com base em cálculos estratégicos e de modelos da lógica do que é apropriado fazer. Nas coordenadorias, as lideranças que atuam em áreas temáticas podem compartilhar o aprendizado e constituir modelos coletivos de atuação, tendo um espaço de reconhecimento de seu papel de agente. Por sua vez, os princípios encontrados nas entrevistas expressam como modelo desejado aquele baseado na importância da atuação coletiva via construção de consensos mínimos entre seus membros, respeitada a independência funcional; no uso de argumentos centrados em princípios constitucionais e em normativas da OIT para enfrentar interpretações restritivas de seu papel e do interesse público; na necessidade de legitimidade dos procedimentos institucionais por meio de construções como a obrigação de pagar pelos danos morais provocados à sociedade, e na busca da articulação com outras instituições e atores sociais para produzir políticas públicas.

Pesquisas futuras, além de apresentar os resultados (policies) gerados pela atividade política do MPT (politics) com vista a afirmar seu papel como agente e definir o interesse público em diferentes áreas temáticas, podem avaliar como tais resultados modificam a ação política dos atores e das instituições envolvidos, incluindo o próprio MPT.

\section{REFERÊNCIAS}

ARARAL JUNIOR, Eduardo et al. Routledge handbook of public policy. New York: Taylor \& Francis Book, 2013.

ANDRADE, Alexander Fernandes. Bom senso para nortear o TAC. Valor Econômico, Rio de Janeiro, 11 jul. 2014.

ARANTES, Rogério Bastos. Ministério Público e política no Brasil. São Paulo: Sumaré Fapesp, 2002. 
ARTUR, K. Direitos humanos e desigualdades: processos políticos, trabalho e justiçadesafios para a saúde do trabalhador. 2014. (Apresentação de Trabalho/Conferência ou palestra).

BAHIA. Ministério Público do Trabalho. Ações sobre política pública contra trabalho infantil são competência da justiça trabalhista. Disponível em: <http://www.prt5.mpt. gov.br/informe-se/noticias-do-mpt-go/481-acoes-sobre-politica-publica-contratrabalho-infantil-sao-competencia-da-justica-trabalhista>. Acesso em: 15 dez. 2015.

BRASIL. Constituição (1988). Constituição da República Federativa do Brasil de 1988. Disponível em: <http://www.planalto.gov.br/ccivil_03/constituicao/ constituicaocompilado.htm>. Acesso em: 5 maio 2015.

BRASIL. Ministério Público da União. - Coordenadoria Nacional de Erradicação do Trabalho Escravo - CONAETE. Relatório de Atividades da CONAETE. 2009. Disponível em: <http://www.pgt.mpt.gov.br/portaltransparencia/download. php?tabela=PDF\&IDDOCUMENTO=643 >. Acesso em: 21 jul. 2015.

BRASIL. Ministério Público do Trabalho. Câmara de Coordenação e Revisão. Processo PGT/CCR/PP/2790/2010: CODEMAT 01.23. 2010. Disponível em: <http://www.mpt. gov.br/ camaraArquivos/CCR_2790_2010.pdf >. Acesso em: 10 maio 2015.

CARELLI, Rodrigo de Lacerda (Coord.); CASAGRANDE, Cássio Luís; PÉRISSÉ, Paulo Guilherme Santos. Ministério Público do trabalho e tutela judicial coletiva. Brasília: ESMPU, 2007.

CNMP - CONSELHO NACIONAL DO MINISTÉRIO PÚBLICO. Ministério Público: um retrato: dados de 2014. Brasília: CNMP, 2015. v. 4

CONCEIÇÃO, Eliane Barbosa. Programa de promoção da igualdade de oportunidade para todos: experiências de ação afirmativa do Ministério Público do Trabalho (20032012). 2013. 382 f. Tese (Doutorado em Administração de Empresas) - Escola de Administração de Empresas de São Paulo, Fundação Getúlio Vargas, São Paulo. 2013.

ENGELMANN, Fabiano. Sociologia do campo jurídico: juristas e usos do direito. Porto Alegre: Sergio Antonio Fabris, 2006.

ESMPU - ESCOLA SUPERIOR DO MINISTÉRIO PÚBLICO DA UNIÃO. Simpósio utopia: o Ministério Público do Trabalho e a utopia: os caminhos para a concretização dos direitos humanos. Brasília: ESMPU, 2015.

FILGUEIRAS, Vitor Araújo. Estado e direito do trabalho no Brasil: regulação do emprego entre 1988 e 2008. 2012. 481 f. Tese (Doutorado em Ciências Sociais) - Faculdade de Filosofia e Ciências Humanas, Universidade Federal da Bahia, Salvador. 2012. 
FREITAS, Ligia. Barros. A aplicação dos princípios constitucionais pelo TST nos julgamentos dos trabalhadores canavieiros. In: ENCONTRO DA ASSOCIAÇÃO BRASILEIRA DE CIÊNCIA POLÍTICA, 9., 2014, Brasília. Anais... Disponível em: <http://www.encontroabcp2014.cienciapolitica.org.br/resources/ anais/14/1403730978_ARQUIVO_LigiaBarrosdefreitas-textocompleto.pdf $>$. Acesso em: 20 ago. 2014.

GILLMAN, Howard. Martin Shapiro and the movement form "Old" to "New" institutionalist studies in public law scholarship. Annual Review of Political Science, Palo Alto, v. 7, p. 363-382. 2004.

GILLMAN, Howard. The court as an idea, not a building (or a game): interpretative institutionalism and the supreme court decision-making. In: GILLMAN, Howard; CLAYTON, Cornell (Ed.). The supremec court in american politics: new institutionalist interpretations. Chicago: University of Chicago Press, 1999.

HALL, Peter A.; TAYLOR, Rosemary C. R. As três versões do neo-institucionalismo. Lua Nova, São Paulo, n. 58, p. 193-223. 2003.

INATOMI, Celly Cook. A atuação do Poder Judiciário nas políticas de erradicação do trabalho escravo rural no Brasil contemporâneo. 2016. 368 f. Tese (Doutorado em Ciência Política) - Instituto de Filosofia e Ciências Humanas, Universidade Estadual de Campinas, Campinas. 2016.

JARDIM, Philippe Gomes; LIRA, Ronaldo José. A Codemat em três momentos: o presente, o passado e o futuro. In: . (Coord.). Meio ambiente do trabalho aplicado: homenagem aos 10 anos da Codemat. São Paulo: Ltr, 2013.

KOERNER, Andrei. Ativismo Judicial? Jurisprudência Constitucional e Política no STF pós-88. Novos Estudos Cebrap, São Paulo, n. 96, p. 69-85, jul. 2013.

KOERNER, Andrei. Instituições, decisão judicial e análise do pensamento jurídico: o debate norte-americano. BIB-Revista Brasileira de Informação Bibliográfica em Ciências Sociais, São Paulo, n. 63, p. 63-86. 2007.

KOERNER, Andrei. Por uma história política do pensamento constitucional Republicano Brasileiro (1920-1888). In: SEELAENDER, Airton (Org.). Direito e História: conceitos fundamentais. São Paulo: Malheiros, 2012.

MACIEL, Débora Alves. A atuação do promotor de justiça na defesade direitos metaindividuais: o uso de procedimentos judiciais e extrajudiciais e a dinâmica de acesso à Justiça. In: ENCONTRO ANUAL DA ASSOCIAÇÃO NACIONAL DE PÓSGRADUAÇÃO E PESQUISA EM CIÊNCIAS SOCIAIS-ÁNPOCS, 24., 2000. Anais... São Paulo: ANPOCS, 2000. Disponível em: <http://portal.anpocs.org/portal/index. php?option=com_docman\&task=doc_view\&gid=4898\&Itemid=357 >. Acesso em: 20 jul. 2015. 
MACIEL, Débora Alves. Ministério Público e Sociedade: a gestão dos conflitos ambientais em São Paulo. 2002. 137 f. Tese (Doutorado em Sociologia) - Faculdade de Filosofia, Letras e Ciências Humanas, Universidade de São Paulo, São Paulo. 2002.

MACIEL, Débora Alves; KOERNER, Andrei. O processo de reconstrução do Ministério Público na transição política (1974-1985). Revista Debates, Porto Alegre, v. 8, n. 3, p. 98-117. set./dez. 2014.

MACIEL, Débora Alves; KOERNER, Andrei. Sentidos da judicialização da política: duas análises. Lua Nova, São Paulo, n. 57, p. 113-134. 2002.

McCANN, Michael. Causal versus constitutive explanations (or, on the difficulty of being so positive...). Law \& Society Inquiry, Chicago, v. 21, n. 2, p. 457-482, Apr. 1996.

McCANN, Michael. Litigation and legal mobilization. In: WHITTINGTON, Keith E.; KELEMEN, R. Daniel; CALDEIRA, Gregory A. (Ed.). The oxford handbook of law and politics. Oxford, New York: Oxford University press, 2008. p. 522-540.

MCCANN, Michael. Poder Judiciário e mobilização do direito: uma perspectiva dos "usuários". Revista da EMARF, Cadernos Temáticos, Rio de Janeiro, p. 175-196, dez. 2010.

McCANN, Michael. Rigths at work: pay equity reform and the politics of legal mobilization. Chicago: London: The University of Chicago Press, 1994.

MELO, Luís Antônio Camargo et al. O novo direito do trabalho: a era das cadeias produtivas. Revista Direitos, trabalho e política social, Cuiabá, v. 1, n. 1, p. 311-335, jul./ dez. 2015.

OIT - ORGANIZAÇÃO INTERNACIONAL DO TRABALHO. Fighting forced labour: the example of Brazil. Geneva: ILO, 2009.

PEREIRA, Ricardo José Macedo de Britto (Org.). Ministério Público do Trabalho: coordenadorias temáticas. Brasília: ESMPU, 2006.

PRADO, Erlan José Peixoto (Org.). Jornada de trabalho: histórias do Ministério Público do Trabalho. Brasília: MPT, 2015.

SCOTT, William. Richard. Institutions and organizations: ideas, interests, and identities. Thousand Oaks: Sage, 2014.

SOARES, José Luiz de Oliveira. A Judicialização da Política Segundo a Atuação do Ministério Público na Área Ambiental. In: MOTTA, Luiz Eduardo; MOTA, Maurício (Org.). O estado democrático de direito em questão: teorias críticas da judicialização da política. Rio de Janeiro: Elsevier, 2007. 
VIANNA, Luiz Werneck et al. A judicialização da politica e das relações sociais no Brasil. Rio de Janeiro: Revan, 1999.

VIANNA, Luíz Werneck; BURGOS, Marcelo Baumann. Entre princípios e regras: cinco estudos de caso de Ação Civil Pública. Dados, Rio de Janeiro, v. 48, n. 4, p. 777843. 2005.

VIANNA, Luíz Werneck; BURGOS, Marcelo Baumann. Revolução processual do direito e democracia progressiva. In: VIANNA, Luíz Werneck (Org.). A democracia e os três poderes no Brasil. Belo Horizonte: UFMG, 2002. 